\title{
Design of Converters for PV System under Partial Shading Conditions
}

\author{
M. Kowsalya, K. Balsubramanyam \\ School of Electrical Engineering, Power Electronics and Drives Division, VIT University, Vellore
}

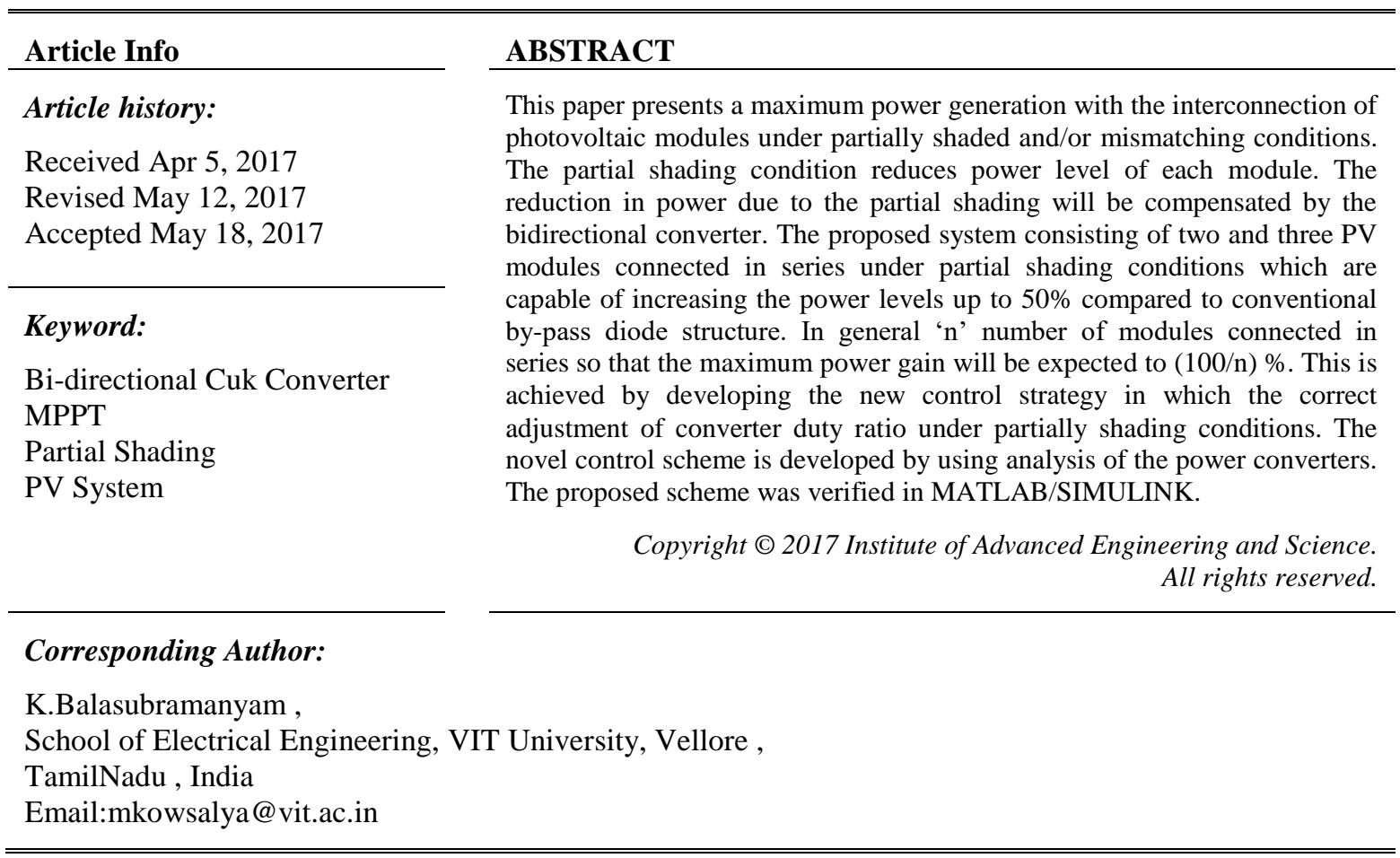

\section{INTRODUCTION}

The depletion of traditional energies and the increase in pollution and greenhouse gases emission, renewable energy contribution makes vital role in energy sources [1,2]. Some of the renewable energy sources are hydro, solar and wind. Of these sources of energy, with corresponding increase in cost of solar photovoltaic energy offers a prominent alternative renewable energy source. Solar energy is free, abundant, pollution free and also distributed throughout the earth [3] with only drawback of initial installation cost. Photovoltaic energy sources have been established for space applications where cost is not a primary consideration. With the present trend of research, cost of photovoltaic cell is expected to go down substantially in future. Because of these tremendous usages of solar energy, photovoltaic cells invade generation of power in houses, intermediate-size commercial installations, or large central power stations. In house hold applications photovoltaic system of kilowatts in size is mounted on the roof top. The available DC power, which varies with solar insolation and temperature, is converter to single phase $50-\mathrm{Hz} \mathrm{AC}$ fed to utility line $[4,5]$.

Now-a-days there are so many research topics related to the photovoltaic generation. As the solar power generation is accepted through out by all, the themes of PV system is to control approaches for maximum power point tracking, this topic determined by the V-I or P-V [6] characteristic curves of the solar panel. Uniform solar power-voltage characteristics of PV array are maximized by Maximum Power Point Technique (MPPT) [7]. Different MPPT algorithms have been proposed in previous literatures, such as perturbation and observation $[8,9]$, hill climbing, incremental inductance $[10,11]$ (INC) etc.

As the weather conditions are intermittent and uncertain using MPPT can set and system working point to the optimum and extract available maximum power from PV [12]. Typical photovoltaic installations, PV arrays are formed by connecting multiple PV modules in various configurations such as series [13], 
parallel, series-parallel, etc. A by-pass diode or by-pass switch is connected in parallel with each PV module for the protection of solar cells against efficiency degradation and hot spot failure effects. In the case where one or more of the PV modules comprising the PV array shaded [14, 15] i.e. due to dust, shading from surrounding buildings, trees or poles, non-uniform solar irradiation then the PV array exhibits multiple local maxima and only one of them corresponds to the global MPP.

The connection of PV cells and modules in parallel, in order to avoid the effect of partial shading is applicable only in low-power PV systems. Under partial shading conditions, the conventional MPPT techniques fail to guarantee successful $[16,17]$ tracking of the global MPP, resulting in significant reduction of both power generation and the PV energy production system reliability. In this paper, bidirectional converter [18] with two or three PV modules is proposed instead of individual PV module for each DC-DC converter to reduce losses due to converter, cost, and size. The integration of PV module-converter unit known as a Module-Integrated PV and Converter (MIPC) [19].

This paper presents a new control scheme of bidirectional converters connected to the two and three PV modules can be raised to voltage and current levels under partial shading conditions.

\section{DESIGN OF PV ARRAY UNDER PARTIAL SHADING CONDITIONS}

A partially shaded module can be modelled by two or three groups of PV cells connected in series inside a module. During partial shading condition, a fraction of the each PV cells which receive different level of irradiance still operate at the normal efficiency. As the current flow through every cell in a series configuration is naturally constant, the shaded shell is operating with a reverse bias voltage to provide the same currents ${ }^{6}$. The resulting reverse polarity leads to power consumption and a reduction in the maximum output power of the partially shaded PV module. The Figure 1 Shows an equivalent circuit representation of Photovoltaic cell under partial shading conditions.

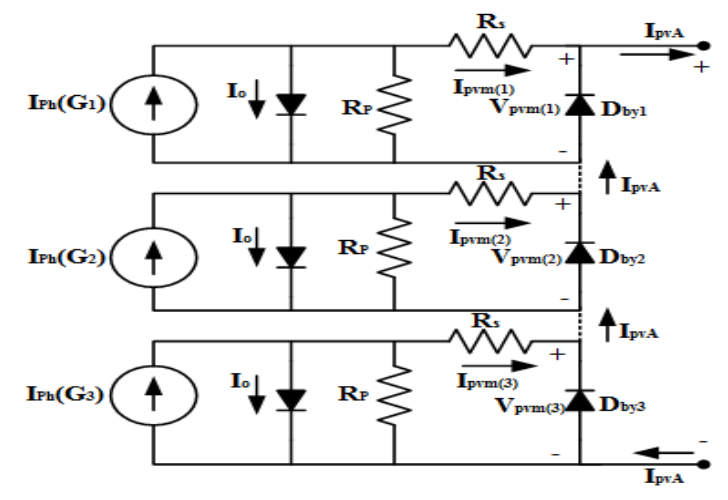

Figure 1. Three PV Modules Connected in Series

The mathematical expression for a single Photovoltaic cell output current is given by equation(1).

$$
I=I_{P H}-I_{S}\left[\exp \left(\frac{q V}{k T_{C} A}\right)-1\right]
$$

The series configuration of three PV modules in an array receiving irradiance levels of $\mathrm{G}_{1}, \mathrm{G}_{2}$ and $\mathrm{G}_{3}$ respectively. Under the uneven insolation $\mathrm{G}_{1}, \mathrm{G}_{2}$ and $\mathrm{G}_{3}$ are assumed to be irradiation levels like $\left(1000 \mathrm{w} / \mathrm{m}^{2}, 600 \mathrm{w} / \mathrm{m}^{2}\right.$, and $\left.200 \mathrm{w} / \mathrm{m}^{2}\right)$ etc. The presence of taking a taking single bypass diode for each PV module into consideration, the output current and output voltage at the array terminal can be obtained by solving the following equations (2):

$$
V_{P V}=\left\{\begin{array}{c}
V_{P 1} I_{P V}>I_{P V 1} \\
V_{P 2}+V_{P 1} I_{P V}>I_{P V 2} \\
V_{P 3}+V_{P 2}+V_{P 1} I_{P V}>I_{P V 3}
\end{array}\right.
$$


Applying equation (2) for the current and voltage for the entire PV array the results represented in figure 2(a) and 2(b) are obtained. The Figure 2(a) and Figure 2 (b) shows the I-V and P-V characteristics of the three PV modules under partial shading conditions $\left(1000 \mathrm{w} / \mathrm{m}^{2}, 600 \mathrm{w} / \mathrm{m}^{2}\right.$, and $\left.400 \mathrm{w} / \mathrm{m}^{2}\right)$.

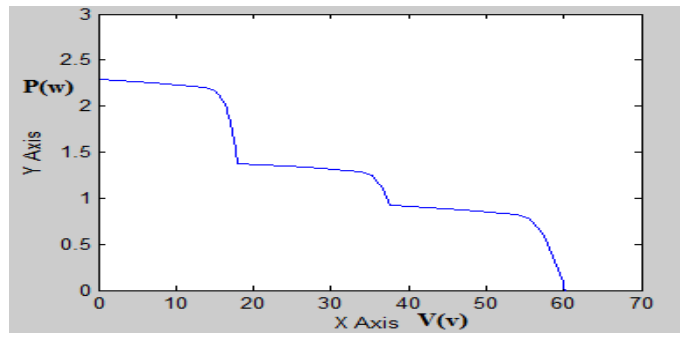

Figure 2 (a). I-V Characterisitcs of PV Panel under Partial Shading

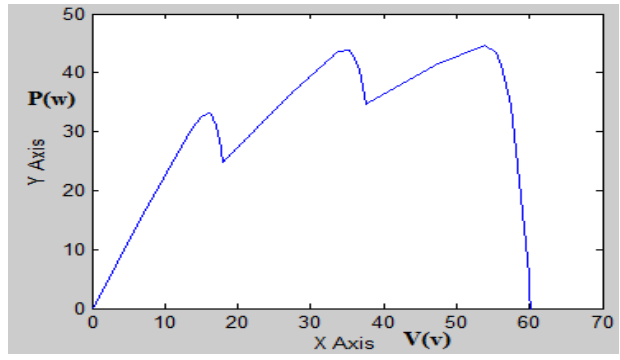

Figure 2(b). PV Characteristics pf PV Panel under Partial Shading

\section{PROPOSED CONVERTERS FOR MODULE INTEGRATED PV UNDER PARTIAL SHADING CONDITIONS}

Many schemes have been developed in which each individual PV module is provided with a DCDC converter forms an integrated PV module-converter unit which is known as a module-integrated PV and converter [18] (MIPC). But, the key problem with this cascaded MIPC scheme is, it may not enable individual PV modules to achieve maximum power point (MPP) operation in the partial shading conditions. The Figure 3shows an alternative scheme based on bypassing MIPCs. In this configuration the MIPCs are connected in series but PV modules are grouped in pairs and each pair is connected to a bidirectional DC-DC converters such Cuk and buck-boost converters.

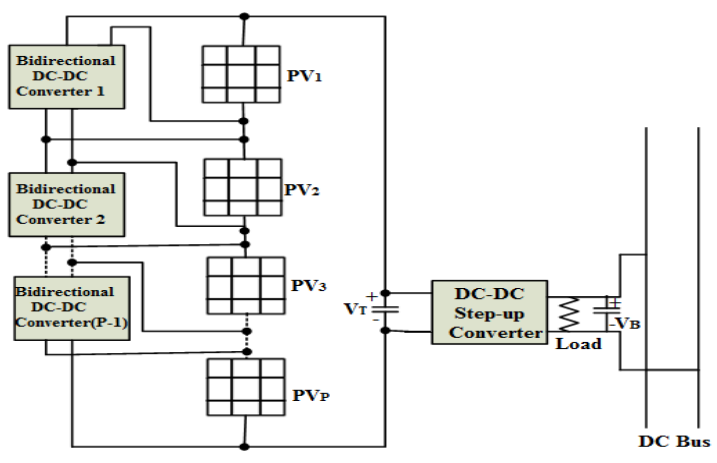

Figure 3. Configurations of MIPC System Using Bypass Approach

In this configuration the MIPCs are connected in series but PV modules are grouped in pairs and each pair is connected to bidirectional DC-DC converters such as Cuk and buck-boost converters. The main advantage of this scheme over the cascaded approach is that the passes power flow under partial shading conditions i.e. different illumination levels. The performance of this scheme has been shown to be much better than the cascaded system. The MPP tracking for the bypassed MIPC can still be based on the schemes which have been widely applied under none partially shaded schemes. Most of these algorithms are only used for one peak point. Hence it requires less computational effort and are simpler to implement comparing to those applied in bypass diode and cascaded MIPC systems.

\subsection{TWO PV MODULE SYSTEMS}

This paper presents a novel model based control scheme for a particular module integrated PV and converter system, where the bidirectional DC-DC converters are used as the bypass converters ${ }^{20}$. The Figure 4shows the MIPC system using bypass for two PV modules and such a system connected to a load through a terminal boost converter. This scheme consisting of two serially connected PV modules and a bidirectional 
converter having one end connected to $\mathrm{PV}_{1}$ and other end is connected to $\mathrm{PV}_{2}$ and step up converter is used for output power conditioning.

When both the photovoltaic modules are uniformly illuminated the bidirectional converter produces zero power. At this time both switches $S_{11}$ and $S_{21}$ are turned off and current direction is passing only through $\mathrm{PV}_{2}$ as well as $\mathrm{PV}_{1}$ to the load. Hence the total power is supplied to the load is given in equation (3).

$$
P_{T}=V_{T} I_{T}=\left(V_{P 1}+V_{P 2}\right) I_{T}=V_{P 1} I_{P 1}+V_{P 2}
$$

And

$$
\mathrm{I}_{\mathrm{T}}=\mathrm{I}_{\mathrm{P} 1}=\mathrm{I}_{\mathrm{P} 2}
$$

Where $V_{T}$ is the terminal voltage, $I_{T}$ is the terminal current, $V_{P 1}$ and $I_{P 1}$ are the voltage and current of $P V_{1}$ at the maximum power point where as $\mathrm{V}_{\mathrm{P} 2}$ and $\mathrm{I}_{\mathrm{P} 2}$ are the voltage and current of $\mathrm{PV}_{2}$.

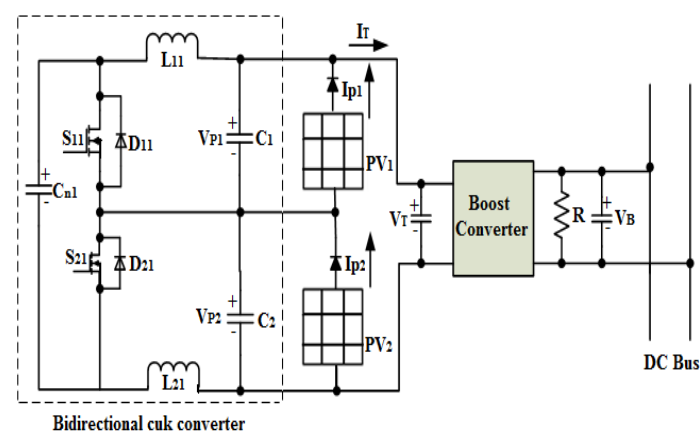

Figure 4. MIPC System Using Bypass Approach Two PV Modules

If the illumination levels of two modules i.e. $\mathrm{PV}_{1}$ and $\mathrm{PV}_{2}$ are different, for example the module $\mathrm{PV}_{2}$ is shaded (i.e. low illumination) the power output from module $\mathrm{PV}_{1}$ is more than the module $\mathrm{PV}_{2}$. By making the switch pair $S_{11}$ and $D_{21}$ is in active position i.e. switching at a fixed frequency with duty ratio $K_{11}$, the converter can mix the power from $\mathrm{PV}_{1}$ away from passing through $\mathrm{PV}_{2}$. The voltage across PV2 relates to that of $\mathrm{PV}_{1}$ is given by:

$$
V_{P V 2}=V_{P V 1}
$$

And the current bypass to the bidirectional converter is given as:

$$
I_{L 11}=\left(I_{T}-I_{P 2}\right)\left(\frac{K_{11}}{1-K_{11}}\right)
$$

The terminal current is given as:

$$
\begin{aligned}
& I_{T}=I_{P 1}-\left(I_{T}-I_{P 2}\right)\left(\frac{K_{11}}{1-K_{11}}\right) \\
& =I_{P 1}\left(1-K_{11}\right)+I_{P 2} K_{11}(7)
\end{aligned}
$$

So the power output to the load without considering the losses is given as:

$$
\begin{aligned}
& P_{T}=V_{T} I_{T}=\left(V_{P 1}+V_{P 2}\left(\frac{K_{11}}{1-K_{11}}\right)\right) \\
& =V_{P 1} I_{T}+V_{P 1}\left(\frac{K_{11}}{1-K_{11}}\right) I_{P 2}(8)
\end{aligned}
$$


The above analysis shows that by varying the duty ratio $\mathrm{K}_{11}$ in equation (8), the maximum power extraction can be achieved by shaded module. The duty ratio $\mathrm{K}_{11}=0$ (i.e. $\mathrm{D}_{21}$ is continuously forward biased), the output power of the system is $P_{T}=V_{P I} I_{P I}$, so the shaded module is totally bypassed and producing zero power. The duty ratio is varying between 0 and 0.5 . Similarly this analysis can be applied to the case when $P V_{1}$ is shaded and switch pair $S_{21}$ and $D_{11}$ is in active position, the duty ratio $K_{21}$ can be adjusted in the range between $0-0.5$ for mixing the power to the converter. The Table 1 shows the comparison of maximum power extracted by using bypass diode and that using MIPC two PV module system.

\subsection{THREE PV MODULE SYSTEMS}

The Figure 5 shows the MIPC system using bypass for three PV modules and such a system connected to a load through a terminal boost converter. This scheme consisting of three serially connected $\mathrm{PV}$ modules and two bidirectional converters ${ }^{19}$ having oneend connected to $\mathrm{PV}_{1}$ and other end connected to $\mathrm{PV}_{3}$ and step up converter is used for output power conditioning.

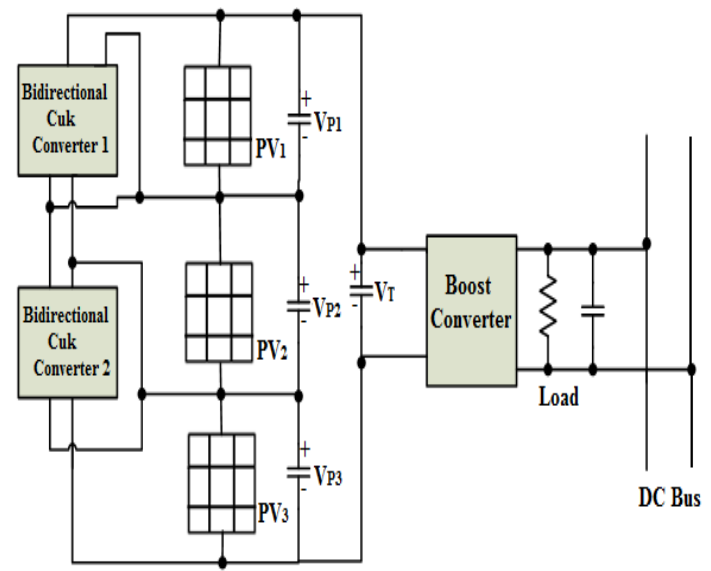

Figure 5.MIPC System Using Bypass Approach Three PV Modules

As can see Figure 5, there are total four device pairs these are $S 11-D_{21}, S_{12}-D_{11}$ for bidirectional converter 1, and $S_{21}-D_{22}, S_{22}-D_{21}$ for bidirectional converter 2 . The system can be operated in four modes as listed shown in below.

1. $S_{11}-D_{12}$ with $S_{21}-D_{22}$,

2. $S_{11}-D_{12}$ with $S_{22}-D_{21}$,

3. $S_{12}-D_{11}$ with $S_{21}-D_{22}$,

4. $S_{12}-D_{11}$ with $S_{22}-D_{21}$.

Following the same approach as in the previous section for a two PV module system, the total output power equation for a three PV module system is given as:

$$
\begin{aligned}
& P_{T}=P_{1}+P_{2}+P_{3}=\left(V_{P 1}+V_{P 2}+V_{P 3}\right) I_{T} \\
& =V_{P 1} I_{P 1}+V_{P 2} I_{P 2}+V_{P 3} I_{P 3}
\end{aligned}
$$

When the illumination levels for modules $\mathrm{PV}_{1}$ and $\mathrm{PV}_{2}$ are different, the power is bypassed to or from converter 1 . The current $\mathrm{I}_{\mathrm{L} 1}$ is non-zero and when it is positive.

$$
\mathrm{I}_{\mathrm{L} 1}=\mathrm{I}_{\mathrm{P} 1}-\mathrm{I}_{\mathrm{T}}>0
$$

The equation (10) can be expressed in terms of power and voltages as: 
Table 1. Comparison of Maximum Power Extracted Using Bypass Diode and That Using MIPC System

\begin{tabular}{ccccccc}
\hline S.NO & $\begin{array}{c}\text { Solar irradiation } \\
\text { for PV1 }(\%)\end{array}$ & $\begin{array}{c}\text { Solar irradiation } \\
\text { for PV2 }(\%)\end{array}$ & $\begin{array}{c}\text { Total Output power } \\
\text { extracted } \mathrm{P}_{\mathrm{T}}(\mathrm{W})\end{array}$ & $\begin{array}{c}\text { Power extracted } \\
\text { using bypass diode } \\
\mathrm{P}_{\mathrm{D}}(\mathrm{W})\end{array}$ & $\begin{array}{c}\text { Gain } \Delta \mathrm{P} \\
=\mathrm{P}_{\mathrm{T}}-\mathrm{P}_{\mathrm{d}}(\mathrm{W})\end{array}$ & $\begin{array}{c}\text { Percentage gain } \\
\left(\frac{\Delta \mathrm{P}}{\mathrm{P}_{\mathrm{d}}} * 100 \%\right)\end{array}$ \\
\hline 1 & 1000 & 1000 & 59.5 & 59.5 & 0 & 0 \\
2 & 1000 & 800 & 57.75 & 25.2 & 32.55 & 129.16 \\
3 & 1000 & 600 & 54.45 & 19.8 & 34.65 & 175 \\
4 & 1000 & 400 & 46.75 & 10.8 & 35.95 & 332 \\
5 & 1000 & 200 & 39.71 & 3.6 & 36.11 & 1003.05 \\
\hline
\end{tabular}

Table 2.Comparison between the Amounts of Powers Extracted Using PV-Integrated Converter and Those Using Bypass Diodes

\begin{tabular}{|c|c|c|c|c|c|c|c|}
\hline S.NO & $\begin{array}{c}\text { Solar } \\
\text { irradiation for } \\
\text { PV1 }(\%)\end{array}$ & $\begin{array}{c}\text { Solar } \\
\text { irradiation for } \\
\text { PV2 }(\%)\end{array}$ & $\begin{array}{c}\text { Solar } \\
\text { irradiation for } \\
\text { PV3 }(\%)\end{array}$ & $\begin{array}{c}\text { Total Output } \\
\text { power } \\
\text { extracted } \\
\mathrm{P}_{\mathrm{T}}(\mathrm{W}) \\
\end{array}$ & $\begin{array}{c}\text { Power } \\
\text { extracted using } \\
\text { bypass diode } \\
\mathrm{P}_{\mathrm{D}}(\mathrm{W}) \\
\end{array}$ & $\begin{array}{l}\text { Gain } \Delta \mathrm{P} \\
=\mathrm{P}_{\mathrm{T}}-\mathrm{P}_{\mathrm{d}}(\mathrm{W})\end{array}$ & $\begin{array}{l}\text { Percentage gail } \\
\left(\frac{\Delta \mathrm{P}}{\mathrm{P}_{\mathrm{d}}} * 100 \%\right)\end{array}$ \\
\hline 2 & 400 & 600 & 1000 & 71.7 & 35.7 & 36 & 100 \\
\hline 3 & 700 & 600 & 1000 & 81.8 & 45.8 & 36 & 78.6 \\
\hline 4 & 1000 & 600 & 1000 & 93.2 & 93.2 & 36 & 62.93 \\
\hline 6 & 400 & 300 & 1000 & 59.9 & 59.9 & 36 & 150.6 \\
\hline 7 & 700 & 300 & 1000 & 70 & 70 & 36 & 94.4 \\
\hline 8 & 1000 & 300 & 1000 & 81.4 & 81.4 & 36 & 79.2 \\
\hline
\end{tabular}

$$
\frac{V_{P 1}+V_{P 2}+V_{P 3}}{V_{P 1}}>\frac{P_{1}+P_{2}+P_{3}}{P_{1}}
$$

The equation (11) can be expressed as:

$$
P_{1}+P_{2}+P_{3}<3 P_{1}
$$

The equation (12) can be expressed in terms of irradiations $G_{1}, G_{2}, G_{3}$ as:

$$
G_{1}+G_{2}+G_{3}<3 G_{1}
$$

The equation (13) can be written as:

$$
\frac{G_{2}+G_{3}}{2}<G_{1}
$$

Thus for specific set of the light levels, if they satisfy the equation (14), switch pair $\mathrm{S}_{11}-\mathrm{D}_{21}$ should be active to ensure positive direction of $I_{L 1}$, otherwise the switch pair $S_{21}-D_{21}$ is activated. The similar analysis can be applied to converter 2 but now it is based on the current direction of $\mathrm{I}_{\mathrm{L} 22}$, so switch pair $\mathrm{S}_{22^{-}}$ $\mathrm{D}_{21}$ is active if the light condition is given as:

$$
\frac{G_{1}+G_{2}}{2}<G_{3}
$$

The combination of light levels and their respective switching status for the two inner converters 1 and 2 are explained in Table 3.

Table 3. Light Conditions to Determine the Active Pairs

\begin{tabular}{lll}
\hline Mode & Light conditions & Active device pairs \\
\hline 1 & $\frac{G_{2}+G_{3}}{2}<G_{1}$ and $\frac{G_{1}+G_{2}}{2}<G_{3}$ & $\mathrm{~S}_{11}-\mathrm{D}_{21}$ and $\mathrm{S}_{22}-\mathrm{D}_{12}$ \\
2 & $\frac{G_{2}+G_{3}}{2}>G_{1}$ and $\frac{G_{1}+G_{2}}{2}>G_{3}$ & $\mathrm{~S}_{21}-\mathrm{D}_{11}$ and $\mathrm{S}_{12}-\mathrm{D}_{22}$ \\
3 & $\frac{G_{2}+G_{3}}{2}<G_{1}$ and $\frac{G_{1}+G_{2}}{2}>G_{3}$ & $\mathrm{~S}_{11}-\mathrm{D}_{21}$ and $\mathrm{S}_{12}-\mathrm{D}_{22}$ \\
4 & $\frac{G_{2}+G_{3}}{2}>G_{1}$ and $\frac{G_{1}+G_{2}}{2}<G_{3}$ & $\mathrm{~S}_{21}-\mathrm{D}_{11}$ and $\mathrm{S}_{22}-\mathrm{D}_{12}$ \\
\hline
\end{tabular}


The Figure 6 (a, b, c, d) shows the four modes of switching operations.

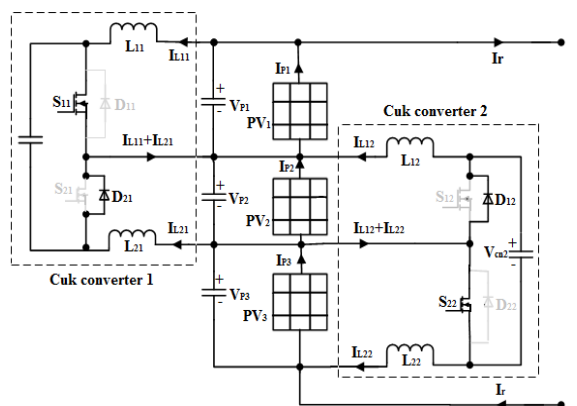

Figure 6 (a). Mode-1: $\mathrm{S}_{11}-\mathrm{D}_{21}$ and $\mathrm{S}_{22}-\mathrm{D}_{12}$ Are Active

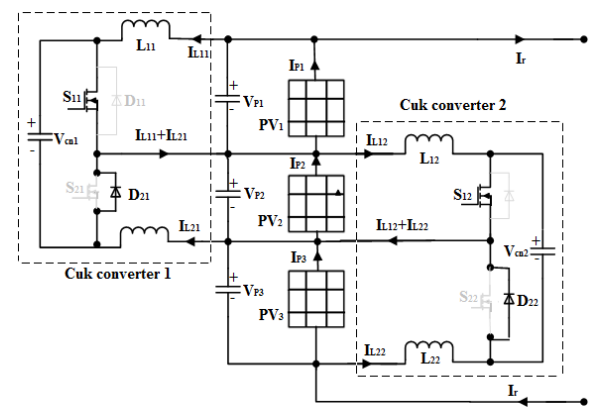

Figure 6 (c). Mode-3: $S_{11}-D_{21}$ and $S_{12}-D_{22}$ Are Active Figure $6(d)$. Mode-4: $S_{21}-D_{11}$ and $S_{22}-D_{12}$ Are Active

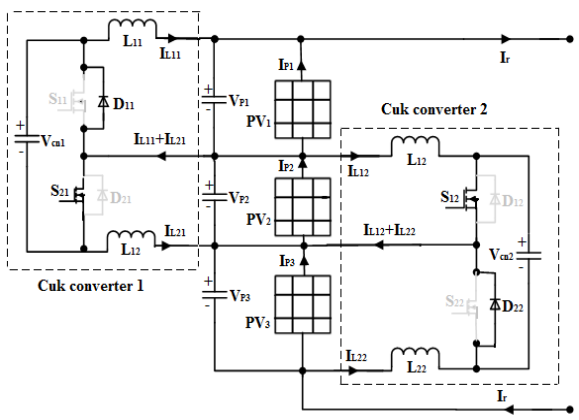

Figure 6 (b). Mode-2: $\mathrm{S}_{21}-\mathrm{D}_{11}$ and $\mathrm{S}_{12}-\mathrm{D}_{22}$ Are Active

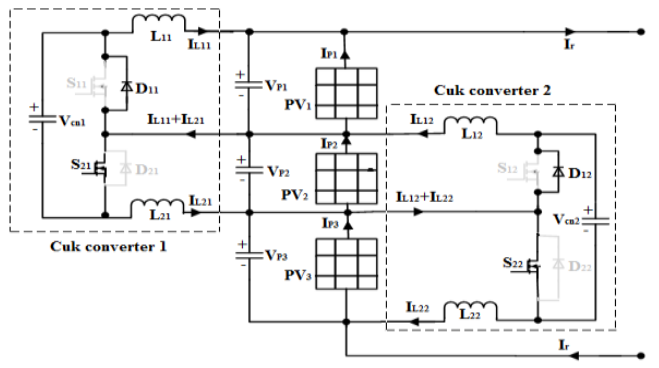

\section{CLOSED LOOP CONTROL OF THREE PV MODULE SYSTEMS UNDER PARTIAL SHADING CONDITION}

The regulation of the converter operation in Section3 was achieved through open-loop controllers, it is highly desirable to have a complete closed-loop control in a practical system which has the potential to eliminate any steady-state errors due to power losses in converter and also prevents any fluctuation of PV voltage and current due to sudden or rapid change in weather conditions. In addition, the control scheme for this system should also enable all three PV modules to operate at their peak power points for any illumination conditions.

All these require coordinated control for the two inner bidirectional converters and the terminal boost converter. A two loop scheme is thus proposed, which consists of a control algorithm for the inner converters adjusting the terminal voltages of individual PV modules and a feedback control scheme to regulate the entire system output voltage by the terminal boost converter. The whole system is shown in Figure 7.

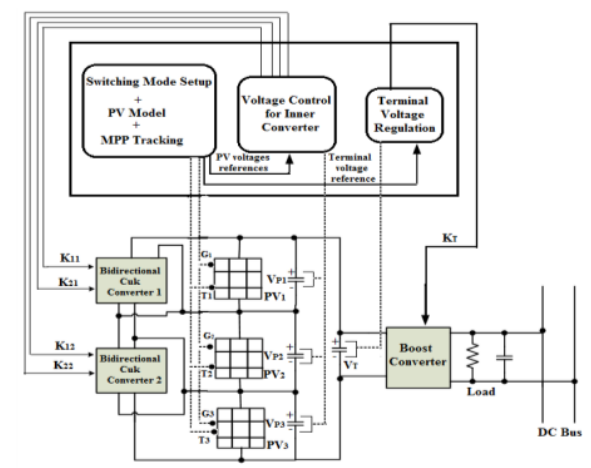

Figure 7. Configuration of the Overall System for A Three PV-module system 


\subsection{CONTROL ALGORITHM FOR INNER CONVERTERS}

According to the measured levels of sunlight and shading conditions within each unit, the switching modes for the two inner converters can be selected based on the scheme described in Section 2.1. Subsequently the duty ratios of the converters are adjusted according to a specially designed control algorithm. For a typical dc-dc converter the voltage on one side, either the input or output side, is held constant by a voltage source and the other side is controllable. However, in this system the voltages at both sides of the inner converter are determined by their respective PV modules which are varying simultaneously when changing the duty ratio for each MIPC unit shown in Figure 6(a, b, c, d). A block diagram of the control scheme is as shown in Figure 8. Here $\mathrm{V}_{\text {upper }}$ is the main controlled voltage to determine the duty ratio $\mathrm{k}_{1}$ and the controller $\mathrm{H}_{1}(\mathrm{~s})$ is set as a lead compensator. The signal from the 'Detuning Loop' is treated as a disturbance to adjust $\mathrm{K}_{\text {upper. }}$. In this way, tight control of $\mathrm{V}_{\text {upper }}$ can be achieved through the 'Main Loop' in Figure 8. Whilst variation of $\mathrm{V}_{\text {lower }}$ may be contained through the 'Detuning Loop' in Figure 8. Similar analysis as above can be done for the regulation scheme of $\mathrm{K}_{\text {lower }}$, which is the control variable for the duty ratio of the MIPC's lower switch but now $V_{\text {lower }}$ is taken as the main controlled voltage while $V_{\text {upper }}$ as disturbance. Nevertheless for stability, either the regulation of $\mathrm{K}_{\text {lower }}$ or $\mathrm{K}_{\text {upper }}$ (but not both) can be done at a time; this condition is still valid as from Section 2, it is known that one device pair in each MIPC can only be active. The overall design scheme can then be applied to both MIPC units in Figure 6(a, b, c, d). Tuning of the lead compensator is based on the transfer functions in (16) and (24). The system is stable, having four poles and two zeros in the left-hand-side of s-plane. The terminal voltage is varying inversely with the duty ratio as indicated by the negative sign. The controller is designed to increase the phase margin through phase lead compensation and to realise zero steady state error using the lag term. This can be analysed through its two derived transfer functions is shown in Figure 8.

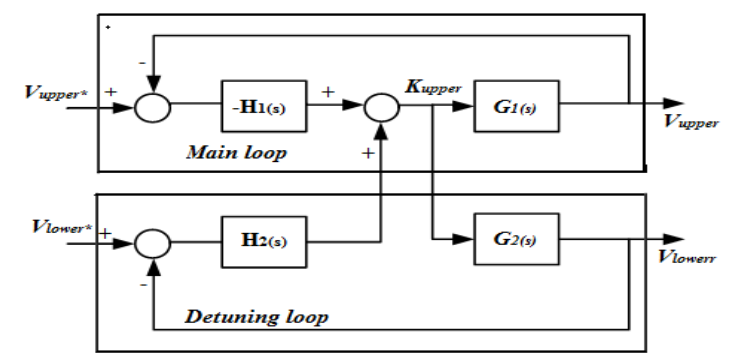

Figure 8. Closed Loop Control Scheme for Controlling the PV Terminal Voltages

The first is between the PV voltage at its upper terminal (which is denoted as $\mathrm{V}_{\text {upper }}$ ) and the control variable whichcontinuously adjusts the duty ratio for the upper switch (which is denoted as $\mathrm{K}_{\text {upper }}$ ); this is given as ${ }^{19}$ :

$$
\begin{aligned}
& G_{1}(S)=\frac{V_{\text {uppr }}(S)}{K_{\text {upper }}(s)} \\
& =-\frac{\beta_{1} S+\beta_{0}}{\alpha_{3} S^{3}+\alpha_{2} S^{2}+\alpha_{1} S+\alpha_{0}} V_{T}
\end{aligned}
$$

Where $\beta_{1}, \beta_{0}, \alpha_{3}, \alpha_{2}, \alpha_{0}$ are the parameters of circuit elements inductor and capacitor. The above parameters can express in terms of capacitance and inductances.

$$
\begin{aligned}
& \beta_{1}=\mathrm{C}_{\mathrm{n}}+\mathrm{CK}+\frac{\mathrm{L}(1-\mathrm{K})}{\mathrm{R}_{\mathrm{P} 2}}\left(\frac{(1-\mathrm{K})}{\mathrm{R}_{\mathrm{P} 1}}-\frac{\mathrm{K}}{\mathrm{R}_{\mathrm{P} 2}}\right) \\
& \beta_{0}=\frac{(1-K)^{2}}{R_{P 1}}+\frac{K^{2}}{R_{P 2}} \\
& \alpha_{3}=\mathrm{c}_{\mathrm{n}} \mathrm{L}\left(2 \mathrm{C}+\frac{\mathrm{L}}{\mathrm{R}_{\mathrm{P} 1} \mathrm{R}_{\mathrm{P} 2}}\right)+\mathrm{c}^{2} \mathrm{~L}\left(\mathrm{~K}^{2}+\left(1-\mathrm{K}^{2}\right)\right) \\
& \alpha_{2}=\mathrm{L}\left(\mathrm{C}_{\mathrm{n}}+\mathrm{CK}^{2}+\mathrm{C}\left(1-\mathrm{K}^{2}\right)\right)\left(\frac{1}{\mathrm{R}_{\mathrm{P} 1}}+\frac{1}{\mathrm{R}_{\mathrm{P} 2}}\right)
\end{aligned}
$$




$$
\begin{aligned}
& \alpha_{1}=C_{\mathrm{n}}+\left(\mathrm{K}^{2}+\left(1-\mathrm{K}^{2}\right)\right)\left(\mathrm{C}+\frac{\mathrm{L}}{\mathrm{R}_{\mathrm{P} 1} \mathrm{R}_{\mathrm{P} 2}}\right) \\
& \alpha_{0}=\frac{\left((1-\mathrm{K})^{2}\right)}{\mathrm{R}_{\mathrm{P} 1}}+\frac{\mathrm{K}^{2}}{\mathrm{R}_{\mathrm{P} 2}}
\end{aligned}
$$
duty ratio.

The second transfer function i.e. equation (4.8) gives lower terminal voltage and lower switch

$$
\begin{aligned}
& G_{2}(S)=\frac{V_{\text {lower }}(S)}{K_{\text {lower }}(s)} \\
& =\frac{\gamma_{1} S+\gamma_{0}}{\alpha_{3} S^{3}+\alpha_{2} S^{2}+\alpha_{1} S+\alpha_{0}} V_{T}
\end{aligned}
$$

Where $\gamma_{1}$ and $\gamma_{0}$ are the parameters of circuit elements inductor and capacitor. The above parameters can express in terms of capacitance and inductances.

$$
\begin{aligned}
& \gamma_{1}=C_{n}+C(1-K)+\frac{L K}{R_{P 1}}\left(\frac{K}{R_{P 2}}-\frac{(1-K)}{R_{P 1}}\right) \\
& \gamma_{0}=\frac{(1-K)^{2}}{R_{P 1}}+\frac{K^{2}}{R_{P 2}}
\end{aligned}
$$

Note that the twotransfer functions also vary according to PV module'sinternal impedances, steadystate duty ratio values, as wellas terminal voltage $V_{T}$, which all take different valuesaccording to the operating point. Thus they both are nonlinearprocesses. Taking into account the effect of duty ratio change onthe two terminal voltages, the closed-loop control schemefor the inner converter is so designed that control of oneterminal voltage takes precedence in determining the converterduty ratio. The other, however, is treated as a disturbancesignal to detune the control signal.

\section{RESULTS AND ANALYSIS}

The performance of the PV-converter integrated system has been evaluated through computer simulation. The model for the two and three PV module systems have been developed using MATLABSIMULINK software package including SIMPOWER tool boxes. The lead compensator controller for both inner and outer converters is modelled by using control tool box MATLAB. A MATLAB algorithm for MPP tracking is also incorporated into the model through an under-defined s-function block.

The open loop system can be operated in two ways one is two PV module systems and other is three PV module systems. The output of two and three PV modules can be connected to dc load with the help of boost converter. The Figure 9 displays the simulated response for the two PV modules with two different partial shading conditions. All PV modules are operating under the same temperature of $250 \mathrm{C}$ and initially, they are uniformly irradiated with $\mathrm{G} 1=\mathrm{G} 2=1000 \mathrm{~W} / \mathrm{m} 2$. The effects on the PV voltages and powers resulting from the changes of light levels $\mathrm{G} 1=1000 \mathrm{~W} / \mathrm{m} 2$ and $\mathrm{G} 2=400 \mathrm{~W} / \mathrm{m} 2$. At $\mathrm{t}=0.51 \mathrm{~s}$, the voltage levels are sharing between two modules and gives maximum voltage level. Due to changes in irradiation levels the voltage levels are decreasing up to $40 \mathrm{~V}$ and maintain constant level starts at time $\mathrm{t}=1 \mathrm{~s}$.

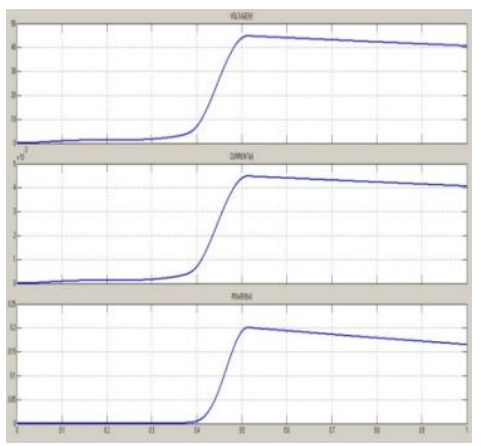

Figure 9. Simulation Output Voltage, Current, Power of MIPC System Using Bypass Approach for Two PV Modules

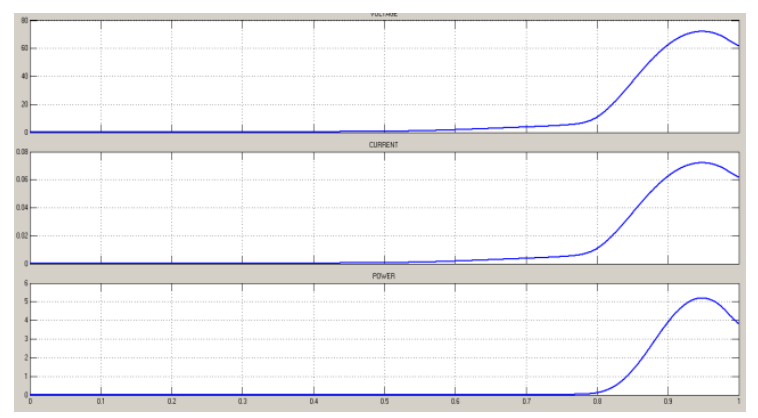

Figure 10. Simulation Output Voltage, Current, Power of MIPC System Using Bypass Approach for Three PV Module 
Figure 10 displays the simulated response for the three PV modules with three different partial shading conditions i.e. $\left(1000 \mathrm{~W} / \mathrm{m}^{2}, 500 \mathrm{~W} / \mathrm{m}^{2}\right.$, and $\left.800 \mathrm{~W} / \mathrm{m}^{2}\right)$. The effects on the PV voltages and powers resulting from the changes of light levels $\mathrm{G}_{1}=1000 \mathrm{~W} / \mathrm{m}^{2}, \mathrm{G}_{2}=500 \mathrm{~W} / \mathrm{m}^{2}$ and $\mathrm{G}_{3}=800 \mathrm{~W} / \mathrm{m}^{2}$. At $\mathrm{t}=0.8 \mathrm{~s}$, the voltage levels are starts rising and increased to maximum voltage level $68.9 \mathrm{~V}$ at $\mathrm{t}=0.95 \mathrm{~s}$. Due to the changes in irradiation levels the voltage levels are decreasing up to $60 \mathrm{~V}$ and maintain constant level starts at time $\mathrm{t}=1 \mathrm{~s}$.

The proposed control system is considered robust in responding to large variation of weather conditions. The simulation has been repeated for the Perturbation-and-Observation (P\&O) tracking method and the amount of power extracted is found to be consistent with that for the model-based approach. The output voltage of the three PV module system is connected to MPPT is shown in Figure 11. The Output voltage contains small oscillations, these can be reduced by using compensator, and here lead compensator is used.

The step response of the above transfer function is shown in Figure 12. In Figure 12 with and without compensator responses are compared.

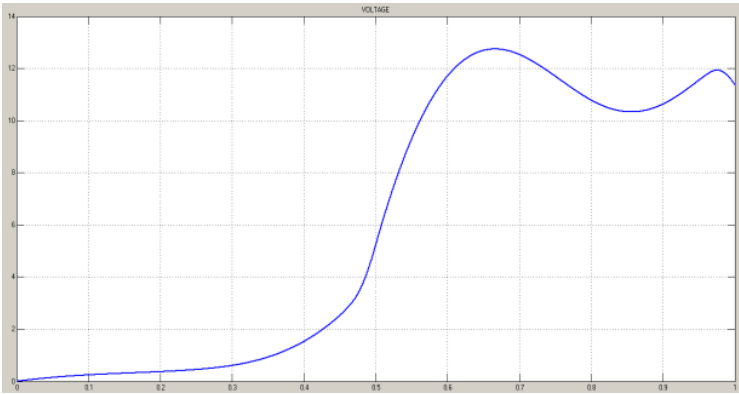

Figure 11.Output Voltage of MPPT connected to MIPC system Using bypass approach for three PV modules

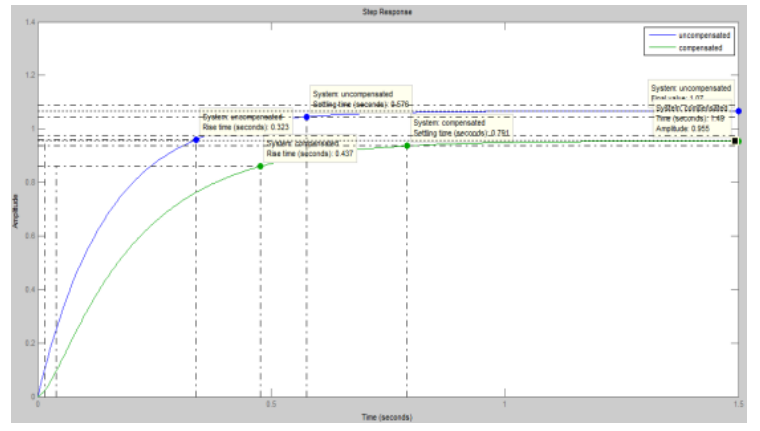

Figure 12.Step Response of With and Without Compensator

Now the three PV module systems, MPPT and compensator responses are connected to DC load with the help of boost converter.

The total output voltage of the configuration of overall system for a three PV-module system as shown in Figure 13. The output voltage is $59.5 \mathrm{~V}$.

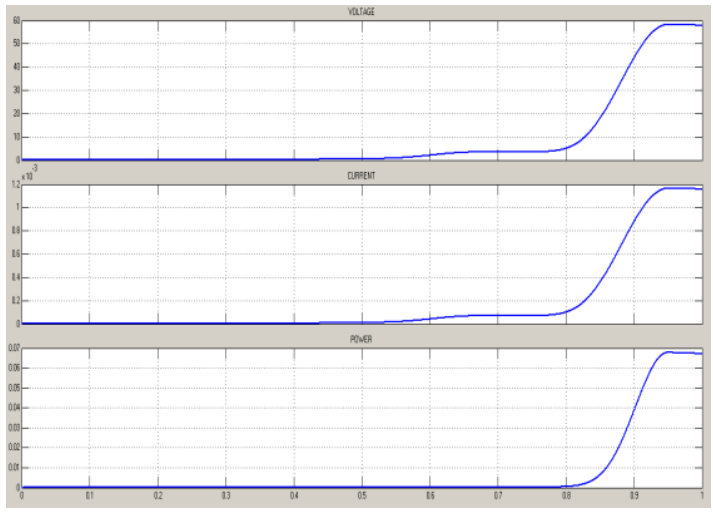

Figure 13.Output Voltage of the Configuration of Overall System for a Three PV-Module System

The performance of this system is compared to the conventional system using only bypass-diode connection. To implement the later, the MPP control algorithm proposedcan be applied. This method searches iteratively the maximum power point among the multiple power peaks. The simulated responses are shown in Figure 13. It can be observed that the major downside for the conventional system is the terminal 
voltage fluctuation of within 10-59 volts range for every change of weather conditions. On the other hand, MIPC has substantially improvedthe system performance by only requiring a narrower operating voltage range. In addition, the extractable power output can be significantly increased by as much as $50 \%$, through keeping all PV modules in optimal operation. This occurs when one of the three PV modules or a third of the total PV generating system is shaded. Using the integrated converter scheme, further power increment can be obtained for other shading levels. This is shown in Figure 13 from which two observations can be made; (1) the maximum amount of the power increment increases with the number of shaded PV modules and (2) the shading level, at which the peak point for the power increment is located, decreases with the number of shaded PV modules.

\section{CONCLUSION}

In this paper a newly developed control scheme of a module integrated PV and converter assembly for achieving maximum power generation in PV system under partially shading conditions. The structure can be developed with the help of two and three PV modules connected in series under various partial shading conditions. The proposed system increases the power levels as much as 50\% compared to conventional bypass diode structure.

The control schemes were optimized using analytical equations for the transfer functions of the power converters, and the dynamic and stable response of the system can be obtained by using Perturbation and Observation method and Lead compensator methods. The proposed control schemes have been presently tested for PV modules under uniformly shading conditions.Provide a statement that what is expected, as stated in the "Introduction" chapter can ultimately result in "Results and Discussion" chapter, so there is compatibility. Moreover, it can also be added the prospect of the development of research results and application prospects of further studies into the next (based on result and discussion).

\section{SPECIFICATIONS}

Table 4. Specifications of PV Module

\begin{tabular}{ccc}
\hline S.no & Characteristics & Specifications \\
\hline 1 & Rated power & $36 \mathrm{~W}$ \\
2 & Peak power & $36 \mathrm{~W}$ \\
3 & Peak power voltage & $16.5 \mathrm{~V}$ \\
4 & Open circuit voltage & $21.4 \mathrm{~V}$ \\
5 & Short circuit current & $2.3 \mathrm{~A}$ \\
\hline
\end{tabular}

Table 5. Speciations of the Inner Converter Elements Resistor, Inductor, Capacitor, and Duty Ratios.

\begin{tabular}{cc}
\hline Parameter & Specification \\
\hline Capacitor & $10 \mathrm{uF}$ \\
Inductor & $8 \mathrm{mH}$ \\
Resistors & $1 \mathrm{ohm}$ \\
Duty ratio & 0.5 \\
Terminal voltage & $\mathrm{U}=48 \mathrm{~V}, \mathrm{~L}=16 \mathrm{~V}$ \\
\hline
\end{tabular}

\section{ACKNOWLEDGEMENTS}

The authos acknowledge the management and faculty of VIT University for pursing this work.

\section{REFERENCES}

[1] ChihchiangHua, Jonngrong Lin and Chihmingshen, "Implementation of a DSP-Controlled Photovoltaic system with peak power Tracking,” IEEE Trans. Industrial ele., Vol.45, pp.99-107, 1998.

[2] Mahmoud Alahmad, Mohamed AmerChaan, SuKit Lau, Jonathan Shi, Jill Neal, "An adaptive utility interactive photovoltaic system based on a flexible switching matrix to optimise performance in real-time," Solar energy 86, pp.951-963, 2012.

[3] Bimal K. Bose, Paul M, Szczesny, and Robert L, Steigerwald, "Microcomputer control of a residential photovoltaic power conditioning system," IEEE trans. Industrial Apl., Vol.5, pp. 99-107, 1985. 
[4] Engin K aratepe, MutluBoztepe, Metincolak, "Development of a suitable model for characterising photovoltaic arrays with shaded solar cells," Solar energy, Vol 81, pp.977-992, 2007.

[5] Yang Du, Dylan Dah-Chuan Lu, "Battery-integrated boost converter utilizing distributed MPPT configuration for photovoltaic systems, " Solar energy 85, pp.1992-2002, 2011.

[6] RamaprabhaRamabadran, "Matlab-Based modelling and performance study of series connected SPVa under partial shading conditions, " Journal of sustainable development,.vol. 2, pp. 85-94, 2009.

[7] Hiren Patel and Vivek Agarwal, "Matlab-Based modelling to study the effects of partial shading on PV array characteristics," IEEE Trans. Energy Con., vol. 23, pp. 302-310, 2008.

[8] Narottam Das, Hendy wongosdihardjo, Syed Islam "Modelling of multi-junction photovoltaic cell using MATLAB/Simulink to improve the conversion efficiency," Renewable Energy, vol. 74, pp. 917-924, 2015.

[9] Mohamed A.Eltawil, Zhengming Zhao, "MPPT techniques for photovoltaic applications," Renewable and Sustainable energy reviews, vol. 25, pp. 793-813, 2013.

[10] ParimitaMohanty,G.Bhuvaneswari,Balasubramanian, NavdeepkaurDhaliwal,"Matlab based modeling to study the performance of different MPPT techniques used for solar PV system under various operating conditions," Renewable and Sustainable energy reviews, vol. 25, pp. 581-593, 2013.

[11] TawfikRadjai, LazharRahmani, SaadMekhilef, Jean Paul Gaubert, "Implementation of a modified incremental conductance MPPT algorithm with direct control based on a fuzzy duty cycle change estimator using dSPACE," Solar energy 110, pp.325-337, 2014.

[12] Eftichioskoutroulis, and freed Blaabjerg, "Anew technique for tracking the global maximum power point PV arrays operating under partial shading conditions," IEEE journal of photovoltaic., Vol.2, pp.184-190, 2012.

[13] Mohamed A.Eltawil, Zhengming Zhao, "MPPT techniques for photovoltaic applications," Renewable and Sustainable energy reviews, vol. 25, pp. 793-813, 2013.

[14] AchimWoyte, Johan Nijs, Ronnie Belmans, "Partial shadowing of Photovoltaic arrays with different system configurations: literature review and field test results," Solar energy, Vol .No 74, pp.217-233, 2014.

[15] K.punitha, D.Devaraj, S.sakthivel, "Development and analysis of adaptive fuzzy controllers for photovoltaic system under varying atmospheric partial shading condition," Applied soft computing, pp.1-13, 2013.

[16] KashifIshaque, Zainal Salam, "A review of maximum power point tracking techniques of PV system for uniform insolation and partial shading condition," Renewable and Sustainable Energy Reviews, vol.19, pp. 475-488, 2013.

[17] M.A.Munoz, M.C.Alonso-Garcia, Nievesvela, "Early degradation of silicon PV modules and guaranty conditions," Solar energy, Vol.85, pp.2264-2274, 2011.

[18] NeerajTiwari, D.BhagwanDas,M.C, "EarlyMppt controller for photo voltaic systems using cuk DC/DC converter," International journal of advanced technology and engineering research, vol. 2, pp. 164-169, 2012.

[19] B.V.P.chong, L.Zhang, "Controller design for integrated converter modules under partial shading condition," Solar energy 92, pp.123-138, 2013.

[20] B.V.P.chong, L.Zhang, "Control of integrated cuk converter and photovoltaic modules for maximum power generation," $3^{\text {rd }}$ international symposium on power electronics for distributed generation systems, pp.175-181, 2012. 